\title{
Some considerations related to quantum electronics, acoustics and science of material based on experiment and theory
}

\begin{abstract}
The coupling of some fundamental sciences and issues arising from it are considered in this paper. The transport and optical characteristics belong to nowadays problems of material science. Some measurements and their interpretations for chosen condensed materials are considered. Various processes, which include directly optical and acoustic processes, are measured for solid and liquid materials. After obtained principal issues of measurement, coupling with them is performed. Principal links include dielectric, resistive, optical and acoustical performances. Nonlinear optical contribution up to optical-laser breakdown can be evaluated from linear data. Micellar laser scattering cover transient effects and is one of the topics in many sciences (including biology and ecology).
\end{abstract}

Keywords: laser, scattering, micelle, sound, ecology, transport performances, diffusion.

\section{INTRODUCTION}

Status of a large number of sciences went into high specialists considerations into their theories and laws of very sophisticated researches. However, quite a number of new considerations are of limited domain since they regard a strictly set model, established boundaries and definite approximations. For applications, complex detailed theory should be simplified to practical one. Having that in view we wished to include ourselves through some analyses into the notion of some contemporary phenomena for a long time investigated from several points of view and to clarify the interpretations, which could provide correct interpretations of highly professional measurements.

The case of impedance. According to the measurements of material carried out, the effective values of impedance are often given as well as its real and imaginary parts. For the given material DC measurement could be made but the interpretation of resistive, capacitive inductive contributions could be the task. The use of data is different in view of the discussion which may follow. The measurements can be correctly carried out; however, an interpretation could be made on several manners. Since the notion or reality is grounded on the different type modeling, questions could be:

Author's address: ${ }^{1}$ Faculty of Electrical Engineering, Bulevar kralja Aleksandra, Belgrade, ${ }^{2}$ Faculty of Technology and Metallurgy, University of Belgrade, ${ }^{3}$ Institute Vinča, Materials Sci. Dpt. University of Belgrade, P. O. Box 522, Belgrade, ${ }^{4}$ Faculty for Computer Engineering and Informatics, ${ }^{5}$ Railway Technical School, ${ }^{6}$ Megatrend University, Belgrade, Serbia

Paper received: 20. 02. 2015.

Paper accepted: 22. 04. 2015. a) On that occasion we penetrate into the essence of different validity of the notion of impedance or in rigorous definition of it. Irrespective whether the measured devices are good we can have into view a complex approach from the real and imaginary parts and applied lumped circuits, till the impedances for the human body's parts. Under the assumption the impedance was measured by all regulation, the reply to the interpretation is sought what it represented in relation to the microscopic materials' parameters. For the system defined, components where: resistance, inductivity, capacitivity features dominant, the irregular geometric shapes have to be taken into consideration. The complex calculations start from the material we need to know all lawfulness and magnitudes of the dielectric constant, magnetic susceptibility (permeability) and specific resistance, $\operatorname{tg} \delta$ (losses), for the case of low frequencies. There is one approach to the response for DC measurements and quite other for the case of high frequency.

b) There are the more complicated (and tensor calculation for the crystal material) and including optical measurements, answers may be obtained faster.

c) The impedance conception in general is interesting from the point of view of the dielectric breakdown, especially for the investigation of optical breakdown and nonlinear processes [1].

A measurement of the food (meat products, "Sote Stroganoff", margarine, soil products) material quality in general by resistance, dielectric constant in complex presentation is known. Many data exist and further develop. The measurements of specific electric conductance of meet and water are performed. Some parallel techniques are acoustical measurements by ultrasonic transmission, or 
sound velocity. Various spectroscopies with and without laser are used for obtaining contents. For wastewater and content of antibiotics, pharmaceutical, detergents, disinfectant materials, urine, etc. are developed by HPLC methods, too. For the best evaluation, electrical resistance or laser scattering measurements, are possible too. Food industry has defined methods, linked to the standards and ecological regulations. HPLC [2] chromatography of high performances method performed by liquid-liquid extraction as methodology and analysis defined by chemical formulation is applied. Many qualities were identified (as correct/or not) after ultrasonic measurements.

The relationship of the electrical specific resistance and the absorption. It seems that arrived at features regarding the conduction and transport characteristics are directly connected to optical responses. The further connection- the material's characteristics connected to dielectric behavior are coupled to optical constants of the material, which in essence represent the transition to higher frequencies. The traditional calculations imply the Kroning- Penny-Kramers modeling [1].
For metal mirror, solid or film, the expression defining the reflectance in the function of electron plasma frequency $\omega_{p}$ and the mean time between collisions, $t_{e}$

$$
R=1-2 /\left(\omega_{p} t_{e}\right) \text { and } A=2 /\left(. \omega_{p} \tau_{e}\right)
$$

The mean time is obtained from electrical conductivity $\sigma$ and

$$
t_{e}=m^{*} \sigma / N_{e}^{2}
$$

$m^{*}$ is effective electron mass, $N_{e}$-free electron concentration and $\omega_{\mathrm{p}}{ }^{2}=4 \pi \mathrm{N}_{\mathrm{e}}{ }^{2} / \mathrm{m}^{*}$. There from,

$$
A(T)=\frac{\omega_{p}}{2 \pi}(\sigma)=A_{0}+A_{1} T
$$

i.e., temperature $(T)$ dependence of absorption is obtained where $A$-absorption, $\sigma$ - DC conductivity, for $T>T_{D} / 3, T_{D}$-Debye temperature. Reflectance of metal mirrors is presented in Table.1.

Another formula is linking optical absorbance (reflectance for $\mathrm{CO}_{2}$ laser wavelength, $10.6 \mathrm{~m}$ ).

Table 1 - Reflectance of metal mirror

\begin{tabular}{|c|c|c|c|c|c|c|c|c|}
\hline Met. & $\omega_{\mathrm{p}}$ & $t_{\mathrm{e}}$ & $\begin{array}{c}\text { Debye } \\
\Theta\end{array}$ & $\frac{d R}{d t}$ & $\begin{array}{c}\text { Theory. } \\
\text { Absorp. }\end{array}$ & $\begin{array}{c}\text { Experiment } \\
\text { Absorption }\end{array}$ & Difference & Comment \\
\hline $\mathrm{Ag}$ & 1.4 & 3.57 & 1273 & 1.62 & 0.46 & 0.5 & 0.04 & Diff.data \\
\hline $\mathrm{Al}$ & 2.23 & 0,81 & 1173 & 3.20 & 1.1 & 1.3 & 0.2 & $"$ \\
\hline $\mathrm{Au}$ & 1.34 & 2.46 & & 2.35 & 0.8 & 0.8 & 0.0 & $"$ \\
\hline $\mathrm{Cu}$ & 1.18 & 1.9 & & 3.88 & 0.8 & 0.4 & -0.4 & $"$ \\
\hline
\end{tabular}

Acoustical-solid state consideration. Less known interconnections between optics and acoustics are related to the formulas of the following type

$$
\begin{aligned}
& v_{\text {tran }}=K_{1}\left((n)^{\overline{2}}-1\right) \\
& v_{\text {long }}=K_{2}\left((n)^{\overline{2}}-1\right), \frac{K_{1}}{K_{2}}=f(\mu),
\end{aligned}
$$

where the acoustical features $\left(v_{t}, v_{l}\right)$ are presented with the Poisson coefficient- $\mu$, refraction index $<n>$ [3-7]. It is linked to integral light scattering LS. More sophisticated measurements (spectral laser scattering methods, i.e. Brillouin with laser's sources provide more accurate and precise sound velocities, elastic coefficients, sound absorption and the sets of thermodynamic parameters (for the given hyperfrequency-hypersound provoked). All these formulas are connected to the crystal symmetry and for the general laws with the optical indicators, electrooptical, electroacoustical and elastooptical constants. Certainly some $c_{s}$ data present classical connection to elasticity moduli, Tabs.2 and Landè factors. For solid state, the contemporary manner of research is related to hyperfine interactions and to spectroscopies with fs techniques being especially mentioned (techniques of Hertzian spectroscopy) which cannot be studied by classical optical spectroscopies with the prisms and diffraction gratings. For magnetic system magnetoacoustical, Brillouin spectroscopy could be of interest on low temperatures. In Table $2 \mathrm{a}$ are presented some results [3], connecting $c_{s}$ and index of refraction $n$ for minerals and rocks.

Polycrystalline and grains by laser scattering can be studied. For known grains distributions is possible by measuring $\mathrm{c}_{\mathrm{s}}$ directly by Brillouin scattering to obtain many data, among which are: grain size, elastic coefficients, pores, etc. but tensor calculus has to be included. The methods of tensor determination for the isotropic distribution of crystallite orientations are relatively easily, but for other cases the task is complicated. Modern presentations of material grains and magnetic performances are important for material descriptions, but with Brillouin scattering; BS tasks are relatively easier .They give we think higher deviations that the $\mathrm{c}_{\mathrm{s}}$ from BS shifts. But, the difference could be the contribution to the dispersity for hypersound. 
Table 2a - Index of refraction and sound velocities to some compounds [3]

\begin{tabular}{|c|c|c|c|c|c|}
\hline Material & Molecular mass & $\mathrm{M} / \mathrm{p}$, Mean atomic weight & $\mathrm{n}_{\text {measured }}$ & $\mathrm{C}_{\text {shear }} \mathrm{km} / \mathrm{s}$ & $\mathrm{C}_{\text {long }} \mathrm{km} / \mathrm{s}$ \\
\hline Fused silica $\mathrm{SiO}_{2}$ & & & & & \\
\hline Percales $\mathrm{MgO}$ & 60.06 & 20.03 & 1.459 & 3.4 & 5.6 \\
\hline & 40.32 & 20.16 & 1.736 & 6.0 & 10.0 \\
\hline Corundum $\mathrm{Al}_{2} \mathrm{O}_{3}$ & 101.96 & & & & \\
\hline PigeoniteMgSiO & & 20.39 & 1.762 & 6.3 & 10.5 \\
\hline
\end{tabular}

Table $2 b$ - Values from Debye temperature, $K$ and experimental values of isotropic elastic moduli [3]

\begin{tabular}{|c|c|c|c|c|}
\hline Material & $\begin{array}{c}\text { Young's modulus } \\
\text { Calculated, } \mathrm{kb}\end{array}$ & $\begin{array}{c}\text { Young's modulus } \\
\text { Experimental, kb }\end{array}$ & $\begin{array}{c}\text { Shear Modulus } \\
\text { Calculated, } \mathrm{kb}\end{array}$ & $\begin{array}{c}\text { Shear Modulus } \\
\text { Experimental, kb }\end{array}$ \\
\hline $\mathrm{MgO}$ & 3180 & $3100 \pm 50$ & 1340 & $1310 \pm 20$ \\
\hline $\mathrm{Al}_{2} \mathrm{O}_{3}$ & 4150 & $4040 \pm 60$ & 1660 & $1640 \pm 30$ \\
\hline $\mathrm{BeO}$ & 3810 & 3880 & 1430 & 1470 \\
\hline $\mathrm{TiO}_{2}$ & 2790 & 2835 & 1085 & 1117 \\
\hline
\end{tabular}

Laser scattering and isothermal compressibility of organic solvents Compressibility $\beta_{c}$ and specific heat as basic functions, characterize the response of the system to the extern interactions. They were measured by various methods. Mechanical measurements can follow only low frequencies, but laser scattering methods cover hypersound processes and parameters. So, dispersion relations can be expended. Rayleigh factors (RF) obtained from He Ne laser $632.8 \mathrm{~nm}$ scattering were used to calculate $\beta_{c}$. Contributions of molecular depolarization and approximations for intern electric fields insert ambiguities (Lorentz-Lorenz, Eykman, Clausius or other relations). The comparisons with other methods can ameliorate the approximations $\rho-\varepsilon$ and derivatives [4-6].

Structure of material and sound velocity. The material structure relationship and the connection with the $\mathrm{c}_{\mathrm{s}}$ have been studied almost 80 -years [4-6]. The principal results are:

- the sound velocity- $c_{s}$ and $\beta_{c}$ change regularly with the molecular growth-M; $c_{s}$ is higher in aromatic than in aliphatic hydrocarbons (although the formers have a higher density- $\rho$ ),

- $\mathrm{C}_{\mathrm{s}}$ increase with the growth of the carbon chain,

- $\mathrm{C}_{\mathrm{s}}$ decreases with the carbon atom number in complex esters and in alcohol radicals,

- the structure isomers have different $\mathrm{c}_{\mathrm{s}}$. The higher $\mathrm{C}_{\mathrm{s}}$ are in orto compounds with the long carbon chains; $c_{s}$ is higher in trans than in cis isomers,

- -the methyl group in esters decreases the carbon chain length while increases the sound velocity,

- the double bond decreases the sound velocity, although the opposite effect is expected,

- the polar material has higher $c_{s}$ than the nonpolar one.
For some liquids, where the Rayleigh integral and frequency scatterings were measured, the principal performances were calculated (RF, depolarization's: horizontal, vertical, for the no polarized and for the polarized laser beams), i.e. the values of the six principal (or 4) components. The evaluations of $c_{s}$ could be given based on scattering results. Then it should be compared classical results for semiclassical formulas for the $c_{s}$ with the material structure. For the characteristic material, it could be find the place of a given substance in its homologous series. The consideration of $\beta_{c}$ in substances is more exact; here in the liquid structures, $\mathrm{C}_{\mathrm{s}}$ is still the consequence of a given, well-defined performance of the material, or in some species of the secondary function of the material response to the given disturbance. Having in view the practical and experimental trends, we shall dwell on the $c_{s}$ (and not on the $\beta_{\mathrm{c}}$ ). In that sense, all of the given claiming must be understood in the inverse sense, that is, if the sound velocity increases, $\beta_{\mathrm{c}}$ decreases. The corrections of the first rules and the contributions shall be followed in the form of the laws of quality that the permanent dipole moments

affect the $c_{s}$ in the liquids (they increases the velocity) as well as the existence of the associations of the molecules in big complexes. Higher permeability liquids have bigger $c_{s}$ ( $\beta$ decreases). Liquids of higher boiling points and of higher vaporization heats have higher velocities. The increase number group-OH, leads to the increase of $\mathrm{c}_{\mathrm{s}}$. The qualitative rules predict that $\mathrm{c}_{\mathrm{s}}$ increases within the higher ratio of specific heats, the molar volume and $\rho$ while it decreases with the growth of the molecular mass; the enhancement of the sound velocity is not due to the carbon chain ramification but due to molecular volume and to the existence of atom complexes (and not due to existence of 
heavier atoms) as was found in the first quantitative rules. 50-years ago the theory started from the Van der Waals equation with the total derivation and calculation the constant $b$. It is the quadrupled

$$
c=\sqrt{\kappa\left(\frac{d p}{d \rho}\right)}=\sqrt{\kappa \frac{R T}{M-b \rho}\left(\frac{M / 3}{M-b \rho}-2\right)}
$$

Here appear $\kappa, M, \rho$ and $b$. The treatment when $V$ is incorporated instead of $\rho$ leads to $c=f(K, M, b$, $\mathrm{V})$ and to the rules where the molecular volume growth is linked to $\mathrm{c}$ across $\mathrm{b}$. Further investigations finalized [1, 2 ] to quantitative links between the sound velocity and the molecule radius. From the connections existing between $r$ and $b, r$ and the molecular refractivity $M_{R}$ is:

$$
c=\sqrt[3]{\frac{3}{16 \pi N} \frac{M}{\rho}\left[1-\frac{\kappa R T}{M c^{2}}\left(\sqrt{1+\frac{M c^{2} / 3}{\kappa R T}-1}\right)\right]}
$$

If we have at our disposure $p_{k}, \rho_{k}, T_{k}$ we have the experimental value of $b$; since in liquids, apart from elastic forces there are impact effects, the rule for the quadrupled $b$ is corrected by introducing the impact parameter $s, b=s B$. The density of the space filling, is $r=B / v, V$ - the volume of the molecule, $r$ - space filling factor. So, the following is obtained:

$$
c=u=\left(\frac{1+r / 2}{(1-s r)^{2}}-\frac{2}{(1-s r)}\right)^{1 / 2} \sqrt{\frac{\kappa R T}{M}} \approx \sqrt{\frac{\kappa R T}{M} \frac{2 s r-1}{(1-s r)^{2}}}
$$

The ratio $(1+r / 2 \sim 1)$ of the specific heats between 1 and 1.5 for the parameter, or the case $\mathrm{C}_{\mathrm{p}} / \mathrm{C}_{\mathrm{v}}=1.2$ [4-6]. The limit values of $c$ are 1600 $1750 \mathrm{~m} / \mathrm{s}$. $\mathrm{s}$ are lower if the molar volume is higher and if the number of the heavier atoms is of higher, or more groups in the compound. For the organic compounds, and for the homologous series the dependence is found: $\mathrm{C}=\mathrm{Wr}-\mathrm{C}_{0}, \mathrm{~W}$ is a characteristic slope of the straight line for the homologous series. For liquids with the zero dipole moments,

$$
s=K\left(1-T / T_{k}\right)^{0.6} \text {, }
$$

$K$ is a characteristic constant, $T_{k}$-critical temperature. Important values for calculating $c_{s}$ are $\mathrm{V}=$ const $\sum_{i}(z A), i, \mathrm{z}$ - number of atom volumes $\mathrm{A}$ per mol with number $i, \beta=(z A)_{i i}$ and with obtaining of the molar mass by the contribution of the weight summations

$$
M=\sum_{i}\left(z G_{i}\right)_{i} \quad c=W \rho \frac{\sum_{i}(z A)_{i}}{\sum_{i}(z G)_{i}}
$$

So $c$ is obtained from the measurements of the density of the material, and $A$ and $G$ are obtained by calculation through chemical formula. This is corrected, in the formula

$$
\begin{aligned}
& c=c_{\infty} c_{n}\left(r-r_{0}\right)=W r-W r_{0}, \\
& c=W \rho B / M-W, \\
& \mathrm{c}=W r B / \mathrm{M}-\mathrm{W} \frac{1}{1+B / \beta}, \ldots \beta=(z \alpha)_{i}
\end{aligned}
$$

Dipole moments and sound velocity. For the material selected the LS was measured on them by $\mathrm{He} \mathrm{Ne}$ laser, the results for the $\mathrm{c}_{\mathrm{s}}$ were obtained .The link with the dipole moments [7] can be followed from integral LS, but also from Brillouin spectra, i.e. shift of the incident line. Starting from the defini-tion of the molecular polarization $P$ and

$$
\mu=\left\{\frac{9 k T}{4 \pi N}\left[P-\frac{c V}{W}\right]\right\}^{1 / 2}
$$

k-The Boltzmann constant, $\mathrm{N}$ - the Avogadro constant-molecular volume. For the case when $\beta \neq 0$

$$
\mu=\left\{\frac{9 k T}{4 \pi N}\right\}\left[P-\frac{c V}{2 W}-\sqrt{\left(\frac{c V}{2 W}\right)^{2}+\beta V}\right] .
$$

Values of $\mu$ from the sound velocity and $\mu$ from $P$ and $M_{R}$.

$$
\mu=\sqrt{\frac{9 k T}{4 \pi N}\left(P-M_{R}\right)} .
$$

The link between the $c_{s}$ and the parachor $P_{P}$ and the surface tension are interesting because the additive rules are explained on the basis of the quantum mechanical calculation so that the semi empirical laws were obtained on the theoretical basis.

$c=5.663 \frac{p^{2} \rho^{2}}{M^{2}} \sqrt[6]{\frac{N}{\rho^{2} M}}, \quad P=\frac{M}{\rho_{l i q}-\rho_{g a z}} \gamma^{1 / 4}$ the molar refraction, hold 
Molar sound velocity has various concepts but the relations are valid in the form [4-6].

$$
\begin{aligned}
& \frac{(1 / c)(\partial c / \partial t)}{(1 / V)(\partial V / \partial t)} \approx-3.03 \approx 3 \\
& R=S=R=S=\sqrt[3]{c} V=\frac{\sqrt[3]{c} M}{\rho} .
\end{aligned}
$$

The additivity is relevant not only to atomic increments $(z)$ but into increments of the liquids. There from stems the possibility to obtain the specific heats with additivity theorem. This can be calculated through molar sound velocity or the links with $\mathrm{P}_{\mathrm{p}}$. For different homologous series the linear link is found as in the velocity and the addition of the atomic decrements For some physical quantities such as: $P, M_{R}$, viscosity- $\eta$. is introduced the constant $b$ (or Van der Waals or RS), the molecular magnetic rotation $-M$ and the critical volume ${ }_{k}$, the linear laws are found (on X, X-represents one form out of the mentioned physical properties, and the constants are found for the homo-logous series. For the unpolar liquids the link with the critical temperature $T_{c}$ and the boiling point $T_{s}$ is deduced

$$
T_{k}=C+D \ln S, T_{s}=A+B \ln S \text {. }
$$

From the definition of the molar refractivity the molecular mass from the $c_{s}$, can be light derived

$$
M=A \rho /\left[c_{s}^{1 / 3}-B \frac{n^{2}-1}{n^{2}+2}\right]
$$

The basic theories of a liquid state deal with quantities among which the $\beta_{\mathrm{c}}$ (or $\mathrm{c}_{\mathrm{s}}$ ) are playing important role. Border cases, extremes in the sense of a chaotic and of the ordered system are gas and solid state. Two theories exist in the kinetic theories of $\mathrm{c}_{\mathrm{s}}$ : (the hole and the cell theories) $[5,8]$. The equations starting from the Van der Waals are considered groundless: they treat liquid molecules as the gas molecules [8], disregarding the corrections. The theory of the free volume $V_{f}$ and $\mathrm{V}$-specific volume are connected through:

$$
c_{m}=\left(2 v / v_{f}\right)^{1 / 3}\left(R T \kappa_{G} / M\right)^{1 / 2} .
$$

The principal mistake was the ignorations of potential interaction of the molecules. The model of the hard sphere, the crystal model of the liquid, the hole model require the particular treatments and the consideration of the properties introduced. The empirical rules deny the theoretical basis. The computer support has been developed through an axisymmetric elastodynamic finite element code, capable of predicting quantitatively accurate displacement fields for elastic wave propagation in isotropic and transversely isotropic material. The numerical algorithm incorporates viscous damping by ad -ding a time-dependent tensor to Hook's law. Amplitude comparisons are made between the geometrical attenuation in the far field and the corresponding prediction to investigate the quality and validity of the code. In addition, throughtransmission experimental measurements made with a $1 \mathrm{MHz}$ wave transducer attached to a sample (Al, apatite, $\mathrm{Co}$ ) sup-port the code prediction.

\section{RESULTS AND DISCUSSION}

\section{Brillouin and Rayleigh spontaneous and stimu- lated scattering, nonlinear optics and acoustics.}

Extensive stimulated Brillouin scattering SBS results from experiments and modeling exists for condensed matter (crystal fiber, liquids, etc.). Our measurements of He-Ne laser scattering $(632.8 \mathrm{~nm})$ for various liquids we implemented in various data. Quantitative estimation of fluctuations in materials is performed through expression of Rayleigh factors RF of definite types. On the basis of depolarizations and isotropic and anisotropic parts of RF, changes in refraction index $n$ were calculated i.e., excited $n_{i}$ through the effects of optostrictions $\left(n_{p}\right)$, induced light birefringence $\left(n_{B}\right)$, as birefringence constant $B_{\lambda}$. Some of our results are presented in table 3.

Table 3 - Contributions of index of refractions from Rayleigh factors

\begin{tabular}{|l||c|c|c|c|c|c||}
\hline \multicolumn{1}{|c|}{ Liquid } & $\mathrm{n}$ & $\begin{array}{c}\mathrm{R}_{\mathrm{is}} \times 10^{6} \\
\left(\mathrm{~cm}^{-1}\right)\end{array}$ & $\begin{array}{c}\mathrm{R}_{\text {anis }} \times 10^{6} \\
\left(\mathrm{~cm}^{-1}\right)\end{array}$ & $\Delta \mathrm{n}_{\mathrm{p}} \times 10^{13}$ & $\Delta \mathrm{n}_{\mathrm{B}} \times 10^{13}$ & $\mathrm{~B}_{\lambda} \times 10^{9}$ \\
\hline \hline Benzene & 1.4949 & 3.02 & 6.017 & 32.29 & 29.69 & 91.949 \\
\hline Toluene & 1.4914 & 4.99 & 6.03 & 53.49 & 29.83 & 91.908 \\
\hline $\mathrm{CCl} 4$ & 1.4559 & 2.263 & 0.81 & 24.85 & 4.1 & 12.03 \\
\hline Phytol & 1.4693 & 2.65 & 5.701 & 28.83 & 28.63 & 85.49 \\
\hline phytol-cyclohex-ane $\mathrm{x}=0.243$ & 1.4326 & 2.90 & 1.25 & 32.36 & 6.437 & 18.25 \\
\hline \hline
\end{tabular}

From Brillouin spectra by $\mathrm{Ar}^{+}$ion laser scattering $(514.5 \mathrm{~nm})$ for various solvents, $\mathrm{cs}_{\mathrm{s}}$ is calculated and compressibility adiabatic $\beta_{s}$, Table 4 Laser power, line width of Brillouin lines, $c_{s}$ (hypersound), are presented, too. 
Table 4 - Contributions of Brillouin spectra for various solvents

\begin{tabular}{|l|c|c|c|c|c|c|c|}
\hline \hline \multicolumn{1}{|c|}{ Liquid } & $\mathrm{P}(\mathrm{mW})$ & $\mathrm{n}$ & $\mathrm{V}_{B}(\mathrm{GHz})$ & $\delta \mathrm{V}_{B}(\mathrm{GHz})$ & $\mathrm{v}_{(\mathrm{m} / \mathrm{s}),\left(\mathrm{c}_{\mathrm{s}}\right)}$ & $Z \times 10^{-5}\left(\mathrm{kgm}^{-2} \mathrm{~s}^{-1}\right)$ & $\beta_{\mathrm{s} \times 10^{10},\left(\mathrm{~m}^{2} \mathrm{~N}^{-1}\right)}$ \\
\hline \hline Benzene & 300 & 1.5073 & 6.3234 & 1.8808 & 1526.23 & 13.40 & 4.889 \\
\hline Phytol & 170 & 1.4707 & 6.5035 & 1.4329 & 1608.77 & 13.67 & 4.547 \\
\hline Quinoline & 200 & 1.6295 & 7.4299 & 1.3509 & 1658.82 & 18.13 & 4.196 \\
\hline $\mathrm{CCl}_{4}$ & 170 & 1.466 & 4.2438 & 0.9921 & 1053.16 & 16.78 & 7.324 \\
\hline Glycerine & 170 & 1.4597 & 9.6154 & 3.6799 & 2396.47 & 29.43 & 1.593 \\
\hline Toluene & 170 & 1.504 & 5.6153 & 0.8961 & 1358.29 & 11.76 & 3.400 \\
\hline
\end{tabular}

In tables 5 are presented symmetries in angular scattering of organic solvent,dodecane.

Table 5a - Lasers scattering intensity for polarized component for dodecane. Part of data obtained by changing incident polarization (unpolarized, polarized and depolarized for both combination) $I_{v h}$ Incident light polarized vertical and horizontal components $V_{h}$ is measured ( $I_{v h}$-rel.un.)

\begin{tabular}{|l|c|c|c|c|c|c|c|c|c|}
\hline \multicolumn{1}{|c|}{ angle } & $30^{\circ}$ & $45^{\circ}$ & $60^{\circ}$ & $75^{\circ}$ & $90^{\circ}$ & $105^{\circ}$ & $120^{\circ}$ & $135^{\circ}$ & $150^{\circ}$ \\
\hline $1 \mathrm{mV}$ sen. & 0.576 & 0.343 & 0.284 & 0.250 & 0.249 & 0.254 & 0.286 & 0.348 & 0.529 \\
\hline corr.vol. $\sin \Theta$ & 0.288 & 0.279 & 0.247 & 0.243 & 0.249 & 0.247 & 0.249 & 0.247 & 0.265 \\
\hline
\end{tabular}

Table $5 b$ - Simetry

\begin{tabular}{|c|c|c|c|}
\hline$I_{30} / I_{150}$ & $I_{45} / I_{130}$ & $I_{60} / I_{120}$ & $I_{75} / I_{105}$ \\
\hline 1.07 & 1.131 & 0.993 & 0.985 \\
\hline
\end{tabular}

Deviation $\mathrm{I}_{30} \mathrm{I}_{75} \quad 16 \% \max$

$$
\begin{array}{llllll}
\mathrm{l} / \mathrm{I}_{90} & 1.2 & 1.121 & 0.993 & \multicolumn{2}{c}{0.9758} \\
1 & 0.991 & 1.0009 & 1.0 & 1.062
\end{array}
$$

Table 6 - Evaluation of anisotropy relative $\gamma^{2}$

\begin{tabular}{|l|c|c|c|c|c|}
\hline \multicolumn{1}{|c|}{ Solvent } & $\begin{array}{c}\text { Relations } \\
\lambda=632.8 \mathrm{~nm}\end{array}$ & $\begin{array}{c}\text { relations } \lambda=546 \mathrm{~nm} \\
\text { Proutier }\end{array}$ & Solution & $\begin{array}{c}\text { Saclay- } \\
\text { Proutier, \% }\end{array}$ & $\begin{array}{c}\text { Proutier pure li } \\
\text { quid,solution, \% }\end{array}$ \\
\hline $\mathrm{CCl}_{4}$ & 0.95 & 2.22 & & 133.68 & \\
\hline $\mathrm{C}_{6} \mathrm{H}_{12}$ & 1.571261 & 1.98 & & 26.1 & \\
\hline $\mathrm{C}_{6} \mathrm{H}_{6}$ & 28.6 & 30.5 & 36.0 & 6.64 & 18.3 \\
\hline $\mathrm{C}_{6} \mathrm{H}_{14}$ hexane & 3.56 & 4.2 & & 17.98 & \\
\hline $\mathrm{C}_{4} \mathrm{H}_{8} \mathrm{O}_{2}$ dioxanne & 3.86 & 2.8 & & 27.46 & \\
\hline $\mathrm{C}_{7} \mathrm{H}_{14}$ methylcyclohex. & $4.42(3.74)$ & & & & \\
\hline $\mathrm{C}_{12} \mathrm{H}_{26}$ dodecane & $14.151(16.094)$ & 18.2 & & 28.62 & \\
\hline
\end{tabular}

Index of refractions and lasers in obtaining Cauchy dependences. By using simple Abbe refractometer and mirrors for deviate $\mathrm{He} \mathrm{Ne}$ and $\mathrm{Ar}^{+}$: ion laser beams (depending on the wanted terms) is possible to obtain precise approximations (Causchy like approximations)

$$
n=A+B / \lambda^{2}+C / \lambda^{4} \text {. }
$$

3. ELECTRICAL AND THERMAL CONDUCTIVITIES AND EXPERIMENT (MACRO/ MICROSCOPIC)

The development of science demand precise knowing of thermal materials performances. One of the most important is thermal conductivity, which determine heat transport and temperature distributions. Mechanism of transfer in solid state is analysed for a long time, but all relations between it
The task of anisotropy formation from laser scattering $(\mathrm{He}-\mathrm{Ne})$ data integral set up

In Table 6 gives calculated anisotropy which was presented by horizontal depolarized components of various organic solvents measurements, i.e. from the measurements which are presented by angular distribution, but ar the first glance only $I_{\mathrm{hv}}$ for $90^{\circ}$ is used in relation to $l_{\text {etalone }} \cdot Y^{2}$ is obtained from the solutions and the measurements $\left(\mathrm{i} / \mathrm{i}_{\text {cycloh }}\right)_{\exp } \mathrm{T}=24^{\circ} \mathrm{C}$. and electric conductance are still actuel, but the approach is known as Wiedemann-Frantz-Lorentz WFL approach and some variety. Debye-EinsteinLorentz approach, Drude formulations, were applied, too. Difference of the first approach (Lorentz numbers -L-constants) is that $L$ obtained from of various functions for semiconductors, dielectrics, isolators. These approches enables the links with other physical performances. Debye formula was with specific heat $c, v$-velocity, average free path- $\lambda$. Concept with electronic gas Wiedemann-Frantz law was changed from

$$
\lambda=\frac{\pi^{2}}{3} \sigma T\left(\frac{k}{e}\right)^{2} \rightarrow \lambda=L \sigma T
$$


where $L$-Lorentz number is depending on the electron gas state and electron interactions (with lattice or mutually, or with defects). The approaches to $L$ number for metals, semiconductors, dielectrics are different but modern measuring methods and developed theories mean that old laws are still topics but on more sophisticated level. Phonon structural conductivity is not completely resolved inspite of intensive investigations. Heat transport by electrons, phonons is completed by particles of higher energies (photons, excitons) especially under higher temperatures including semiconductors. The additivity laws hold

$$
\lambda=\lambda e+\lambda f+\lambda d o b
$$

$\mathrm{L}$-function is more complex for semiconductors and dielectrics, isolators as well, so the experiment has to be included. The formula $\lambda=\left(\alpha T^{n}+\beta / T\right)^{-1}$, is in use, where $\alpha, \beta, \mathrm{n}$, coefficients. Microscopic and macroscopic conceptions, enable many methods for direct thermal conductivity measurements, or in the group of some constants including specific heat, density, or coefficients of thermal expansion. Methods in general have high practical value beside of sophisticated other methods. Some of them are based on pulse lasers; on the other hand LS methods have many approximations in partial derivations of important magnitudes. Critical analyses of separation of conductivity to components exist, but in different cases, only some contributions are implemented due to different coefficients of relaxations. (Thermal modelling interaction with fs laser pulses and phenomena by metals, semiconductors and semimetals have different contributions in thermal conductivity). Characteristic temperatures as $\Theta$ (Debye temperature) are crucial for conclusions. Electronic metallic component, semiconductor and semimetals are determined through WFL laws. Its separation from the total $\lambda$ (experimental data) use some indirect and direct methods, between which are among others, pulsed laser methods.

\section{STUDY OF MICELLES IN SODIUM DODECYLSULPHATE-SDS BY DYNAMIC LASER SCATTERING}

Both approaches to the light scattering on a more classical level by considering the extinction coefficient (turbidity) $\tau$ which is measured by the integral technique, as well as modern access with regard to diffusion coefficients $D$ are applied in industry, pharmacy, etc. In theory both have many advantages as contactless measurements. It means that $D_{i}$ overtook the role of $M_{i}$. Since they are measured by the photon beating techniques (spectral techniques) they offer more possibilities. Having in view the complexity of micellar milieu, the presented considers some measurements of the diffusion coefficients for liquid solutions of SDS in the micellar phase, but without salt additions. It is considered that salt accelerate the micelles creating by rendering the situations instable. The laser scattering in the dynamic case for a chosen micellar medium (or macromolecular material) is performed and the corresponding theory is analyzed. SDS, although being the subject of numerous investigations is still up to day of considerable importance as medium. There is a lot of well explainable phenomena concerning the surface active colloids and their interactions in the chain of single molecules-macromoleculesmicelles, have been for a long time a subject of interest from the point of view of science. Many models of light scattering are based on understanding chemical and physical phenomena in different media [1-15]. This is the reason why many measuring methods have to describe definite situations. Laser scattering (generally light scattering) is applied in a lot of industrial branches and humane sciences. Colloids are particularly related to theories and techniques of light scattering LS (static and dynamic) from the viewpoint of physics of fluctuations, which on the field of LS in chemistry are linked to the statement concerning non-ideal state of solutions, and fluctuations of concentration. In the first measurements using homodyne and heterodyne techniques in the optical range and a LS in the treatment of the ion effects and polydispersity, we had examples of non-Gaussian statistics [16] (Polydispersity, semicoloids, SA materials have the same problems.) Electrochemistry is particularly related to them. The shapes of the scatterer were studied from the point of view of electromagnetism, starting from the exact Maxwell equations, depending on the relation of the wavelength and the size of the scattering center (in the treated case the monomer size, aggregation into: dimmer to micelles, polymerization chain) and refraction index, etc. There is a wide area of research where the experiment offer considerable contributions with the smallest perturbations. Here are considered some sections of the theory, some results applied and the results concerning SDS as the substance primarily used for the study of micellization phenomena. Till today's it has not lost its importance in considering the observation of superficial phenomena and the role of small ions in the stability of the medium. It is considered that colloidal chemistry got a new stage based on fundamental laws by improvements related to the existing laws and their application to new subjects, solutions with small and big molecular mass and superficially active material. All mechanisms are subject of interpretations having in mind the development of the measuring techniques.

Some theoretical consideration. The theory and experience have a large application concer- 
ning the measurements based on techniques of LS. The initial points are related to a deductive manner to the multicomponent systems and to the processes belonging to the statically LS. The suitability of the access is related to possible applications of numeric data and capacities of contemporary computers. The standard static theory of scattering has found a long time ago its confirmation in spectral measurements whose integration procedures have been used in this paper. Numerous references data [5-13] about the solutions and LS are nowadays connected with diffusion coefficients (translational and rotational) or with the mass of molecules. But independent of the trend and articles [5,12], there is a lot of approaches using molecular masses since in this way the measuring schemes become simplified. The interpretation of routine and standard industrial measurements in the LS of polymers and powder technology is relatively reliable and stable. The LS with coherent laser sources has been accepted a long time ago as a standard technique in defining polydispersity $[13,15,16]$, for evaluation internal potential. and further development of theory (Derjaguin-Landau-Verwey-Overbeek-DLVO, etc.). It could be noted that these replacement of incoherent sources by coherent ones introduced more sophisticated measurements and helped in clearing uncertainties existing in solving constant for standard, The behavior of molecules in the solution is of permanent interest for considering the point where the beginning of interaction is to be expected. The principal object of consideration are polyions in supporting electrolytes, surface active substances, synthetic polymers, polyelectrolytes in general, polymers in binary solution and poly electrolytes -protein with very low charge density at least up to Donans equilibrium. Very useful are theoretical concepts [15].The theory starts with the fluctuateons of the dielectric constant- $\varepsilon$ or the index of refraction-n where $I$ is the number of the solution components

$\partial n=\left(\frac{\partial n}{\partial T}\right)_{p, m} \partial T+\left(\frac{\partial n}{\partial p}\right)_{T, m} \partial p+\sum_{i=1}^{l}\left(\frac{\partial n}{\partial m_{i}}\right)_{p, m} \partial m_{i}$

The index $I$ is used for the solvent and the subscript $m$ indicates that all molalities except the one, which is being differentiated, are to be held constant.

$\partial n=\left[\left(\frac{\partial n}{\partial \ln \rho}\right)_{m} \frac{\left(\sum_{i=2}^{l} V_{i} \partial m_{i}-\partial V\right)}{V}\right]+\sum_{i=2}^{l} \psi_{i} \partial m_{i}$ where $\left\langle\mathrm{V}_{\mathrm{i}}\right\rangle$ is the partial molal volume, $\psi_{i}=\left(\partial n / \partial m_{i}\right)_{T, p, m}$.

When the averaged fluctuations of the volume and molality $\left(<. \partial V^{2}>,<. \partial m_{i} \partial m_{j}>,<. \partial m_{i} \partial V>\right)$ are included and the calculations of the statistical physics applied, the following equations was derived [17]:

$\left\langle\partial n^{2}\right\rangle=k T\left\{\left[\frac{\beta_{T}\left(\frac{\partial n}{\partial \ln \rho}\right)^{2}}{V}\right]\right\}_{m}+\sum_{i=2}^{l} \sum_{j=2}^{l} \psi_{i} \psi_{j}\left(\frac{\partial m_{i}}{\partial \mu_{j}}\right)_{T, p, \mu_{j}, m_{l}} \mu_{j}$

i.e. fluctuations $<\partial n^{2}>$ are linked to compressibility $\beta_{\mathrm{T}}$ and chemical potential i. The turbidity coefficients $\tau_{\mathrm{E}}$ can be calculated as follows:

$$
\tau_{E}=\frac{32 \pi^{3} n^{2} R T V}{3 \lambda_{0}^{4} N_{A}} \sum_{i=2}^{l} \sum_{j=2}^{l} \psi_{i} \psi_{j} \frac{A_{i j}}{\left|a_{i j}\right|}
$$

where $\lambda_{0}$ wavelength, $a a_{i j}=\left(\frac{\partial \mu_{i}}{\partial m_{j}}\right)_{T, p, m}=\left(\frac{\partial \mu_{j}}{\partial m_{i}}\right)_{T, p, m}$ and $\mathrm{N}_{\mathrm{A}}$-Avogadro's number. This is only one of the expressions in the variety of different models of the turbidity coefficients as a form of scattering and absorption processes efficient cross-section(per area or volume). Here $A_{i j}$ are the cofactors of the determinant $\mathrm{a}_{\mathrm{ij}} ; \mathrm{A}_{\mathrm{ij}}=\frac{\partial\left|a_{i j}\right|}{\partial a_{i j}}$. Very high interest exists for the study of the character of detergent solubility and for the critical micelar concentration (CMC), Fig. 1 and Tab. 7.

Table 7 - The variations of CMC versus salt concentrations for SDS

\begin{tabular}{|c|c|c|c|}
\hline No. & $\begin{array}{c}\text { Salt } \\
\text { concentration }\end{array}$ & $\begin{array}{c}\mathrm{CMC} \text { for } \\
21^{0} \mathrm{C}\end{array}$ & For T \\
\hline 1 & 0 (in aqua) & $0.078 \mathrm{M}$ & $\exp (-2834 / R T)$ \\
\hline 2 & $0.01 \mathrm{MNaCl}$ & $0.0057 \mathrm{M}$ & $\exp (-3017 / R T)$ \\
\hline 3 & $0.03 \mathrm{MNaCl}$ & $0.0033 \mathrm{M}$ & $\exp (-3347 / R T)$ \\
\hline 4 & $0.1 \mathrm{MNaCl}$ & $0.0013 \mathrm{M}$ & $\exp (-3801 / R T)$ \\
\hline 5 & $0.3 \mathrm{MNaCl}$ & $0.00373 \mathrm{M}$ & $\exp (-4224 / R T)$ \\
\hline
\end{tabular}

The micelar range for an ionic detergent is very sensitive to ionic environment.The Debey expression for scattering intensity is [5].

$$
\frac{H\left(c-c^{*}\right)}{\tau_{E}}=\frac{1}{m_{a} M_{s}}+2 B c
$$


where $\tau_{E}$ is the turbidity in excess, $\mathrm{m}_{\mathrm{a}}$-number of $\mathrm{C}^{*}$-CMC. Based on Gibbs free energy systems, with aggregations, $\mathrm{M}_{\mathrm{s}}$-the molecular mass of the surface active monomer, $\mathrm{H}$-factor involving optical parathe derivation of the chemical potential, Prins and Hermans derived the formula for the extreme case meters, B-second virial coefficient, c-concentration,

$$
\frac{H\left(c-c^{*}\right)}{\tau_{E}}=\left\{\begin{array}{ll}
\left(\frac{1}{b_{3} M_{m}^{3}}\right)\left\{1+\left[\frac{\left(c-c^{*}\right)}{2 n_{3} M_{m}}\left(p^{2}+p-\frac{p}{b_{3}}\right)\right]\right\} & \text { I } \\
\left(\frac{1}{b_{4} M_{m}^{3}}\right)\left\{1+\left[\frac{\left(c-c^{*}\right)}{2 c^{*} m_{a}}\left(p^{2}+p-\frac{p}{b_{4}}\right)\right]\right\} & \text { II }
\end{array}\right\}
$$

The cases I and II correspond to high concentrations of salt i.e. $\mathrm{N}_{4}<<\mathrm{N}_{3}$ and to absence of salt, $N_{3}=0$, respectively. $b_{4}=1-f \alpha+f^{2} \alpha^{2} / 2+f^{2} \alpha / 2 m_{a}$, $b_{3}=1-\alpha+\alpha^{2} / 2+\alpha / 2 m_{a} f=\psi_{3} / \psi_{4}$.

Note that subscript 3 and 4 are reserved for salt component and surfactant monomer, respectively, $m$-for micelles, $n_{3}, n_{4}$ are the salt and surface active monomer concentrations in $\mathrm{mol} / \mathrm{ml}, \mathrm{p}$ - is the charge, $\alpha$-effective degree of dissociation, and $m_{a}=M_{m} / m$. The considerations of apparent micelar weight of SDS versus refractive index increment and number of aggregations versus concentration presents the Rayleigh scattering from the same object (micelle and the solutions with salt) and a more complex expression was derived. A difference of $5-18 \%$ compared to the theory and experiment was found. The derived theory express the light intensity scattered from the point $r$ under angle $\Theta$ and although more complex calculations are included, the basis is analogous to the Rayleigh ratio. Among scattered objects a great polar head and an affinity to solvent characterize the surfaceactive molecules with polar and ion-nonpolar group without affinity. Rather different model of the aggregation can be supposed and cheeked by LS (including the number of aggregations charge, etc): some of them are cylindrical (Figs.3-5). These LS concern the molecules SDS- $\left[\mathrm{CH}_{3}\left(\mathrm{CH}_{2}\right)_{11} \mathrm{OSO}_{3}\right]$ $\mathrm{Na}^{+}$with the molecular mass 288.384 as an example of the an-ionic superficially active molecule. The sulphate ion is polar and the hydrocarbon chain is a no polar group in aqueous solution.Fig. 6, 7 present obtention of $M$ from limiting value $\mathrm{H}$ (c$\left.\mathrm{C}^{*}\right) / \mathrm{T}$ and $\mathrm{T}$ for SDS with (or without) salt. It seems that the solution scatters less if no salt is added. This is valid up to a concentration 4 when the presence of $\mathrm{NaCl}$ has no influence. The second approach to the dynamic situations is linked to the correlation functions induced by fluctuation in the material consisting of a more than one type of molecules. The principal features of micelle: shape, number of monomer aggregations and the characteristic Stern layer, Fig 6, influence the LS data.

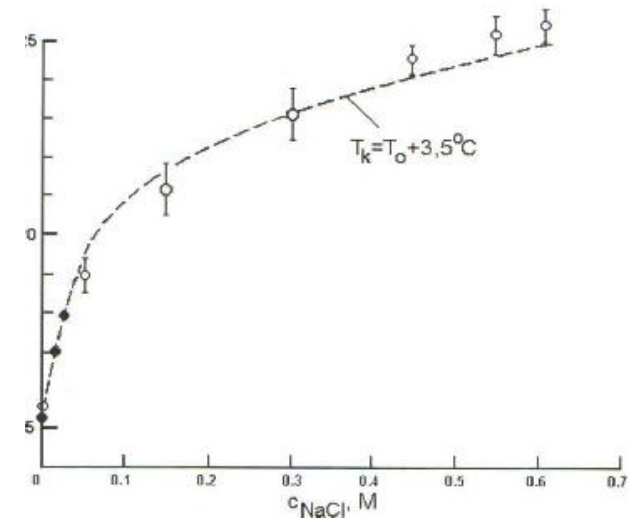

Figure $1 \mathrm{a}-T_{c}$ of the micelle formation as the function of the concentration of NaCl--- Murrey-Hartley theory results of [4] and o-Nakayama and Shinoda [15].

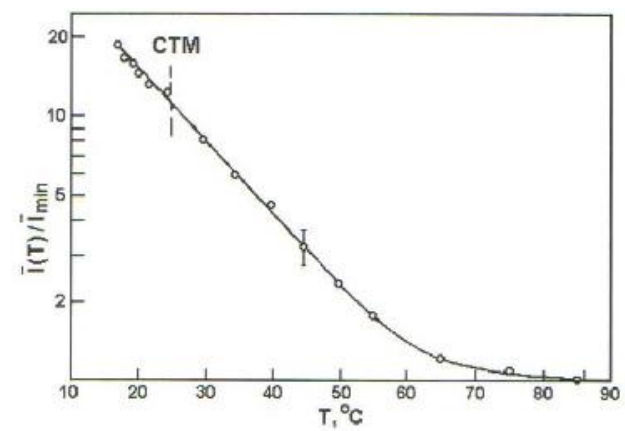

Figure $1 b$ - Relative scattering intensity I/Imin versus temperature for $6.910^{-2} \mathrm{M}$ of SDS in $0.6 \mathrm{MNaCl}$ solution- $T_{\text {сСтм }}{ }^{-} .15 . \%$ of differences are marked [15]

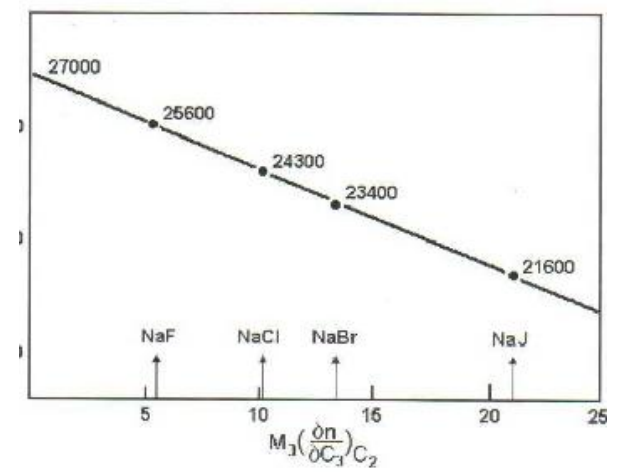

Figure 2 - Extrapolation of square root of app. micellar weight of SDS $M_{2}$ in $0.3 \mathrm{M}$ sodium halide [15] 
6

$$
{ }^{10} \mathrm{M}_{3}\left(\frac{\partial \mathrm{n}}{\partial \mathrm{C}_{3}}\right)_{\mathrm{C}_{2}}^{15} \quad 20 \quad 25
$$

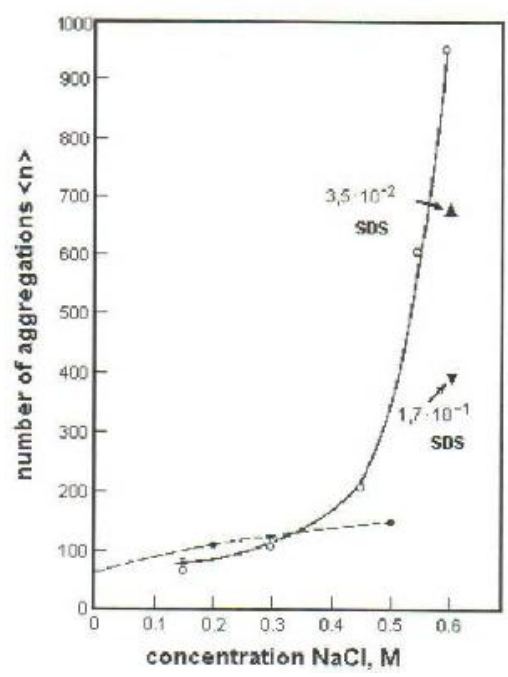

Figure 3 - Average number of aggregation versus $\mathrm{NaCl}$ concentration $\left(25^{\circ} \mathrm{C}\right)[15]$

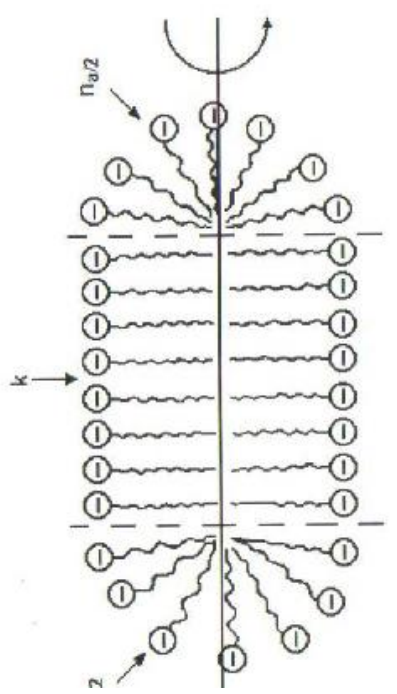

Figure 4 - Micellar structure with a number of aggregations $n+$

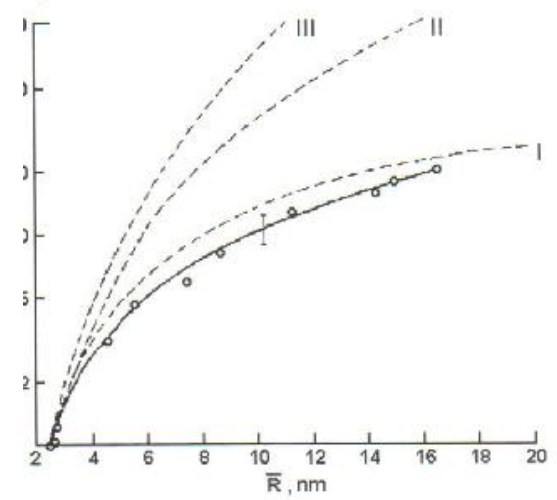

Figure $5-1 / I_{\min }$ as function of $R$-.o-exp,--theor., I-elipsoid,II elipsoid short, III sphere (15\%scatter)

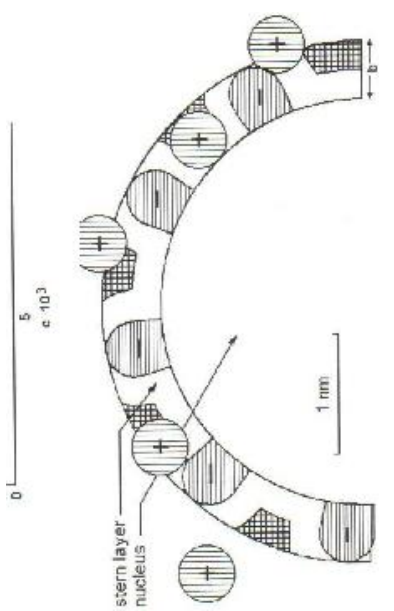

Figure 6 - SDS micellar cross sections Na hydrate ions occur in the marked range Stern layer, nucleus

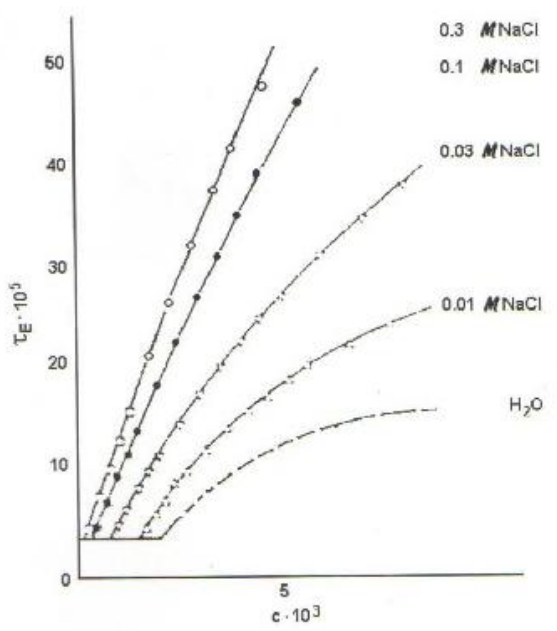

Figure 7 - Turbidity coefficient- $\tau$ for SDS at different concentrations of $\mathrm{NaCl}\left(21^{\circ} \mathrm{C}, 436 \mathrm{~nm}\right.$ [17]

Experimental data. Part of results of SDS measurement of dynamic LS under small angles disposition based on He-Ne laser are used to calculate linewidth $\Gamma$ for $632.8 \mathrm{~nm}$ for $5 \mathrm{~g} / \mathrm{l}$ in aqua bidestilata (without $\mathrm{NaCl}$ ), Table 8 . $\mathrm{D}_{\mathrm{T}}$ were obtainned by $D_{T}=2 \pi \Gamma / q^{2}$ and respecitive radii of formatted micelles.

Table 8 - Working conditions and part of results for $5 \mathrm{~g} / \mathrm{ISDS}$ dynamic LS

\begin{tabular}{|l|c|c|c|c|}
\hline No. & $U_{\text {PM }}, \mathrm{V}$ & Filter $\mathrm{Hz}$ & $\Theta_{\text {app }}$ & $\Theta_{\text {reel }}$ \\
\hline 1 & 1150 & 5 & 4 & 3.006 \\
\hline
\end{tabular}

\begin{tabular}{|l|c|c|c|c|}
\hline No. & $\mathrm{q}^{2} \mathrm{~cm}^{-2}$ & $\Gamma$ & $\Gamma_{\text {real }}$ & $D_{\mathrm{T}} 10^{6} \mathrm{~cm}^{2} \mathrm{~s}^{-2}$ \\
\hline 1 & $4.910^{7}$ & 3.408 & 8.716 & 1.141 \\
\hline
\end{tabular}

$<D_{T}>=1.20810^{-6} \mathrm{~cm}^{2} / \mathrm{s}=1.22510^{-6} \mathrm{~cm}^{2} / \mathrm{s}$

and hydrodyn. radii $\bar{r}=3.79 \mathrm{~nm}$ 


\section{CONCLUSION}

Optimization methods for pollutions detection in ecology, material quality measurements are of constant interest, including food industry, wastewater, atmosphere, etc. and it should be further developed. Potentially negative impact on aquatic and terrestrial organisms should be monitored. By comparing various techniques, their selection could be influenced having in mind resolutions, time, uncertainty, etc. Some of them are simple for sample preparation, other not. We only mention that opti$\mathrm{cal}$, acoustical and electrical methods can give the content on the products and be confirmed by other methods. World demands searching for new technologies and material production which is followed by emergent substances-ES. They follow physical and chemical detections in water, but it has to be mentioned that lidar remote sensings is currently present. The relations of $\gamma^{2}$ and $\lambda$ is very weak. Deviations of pure liquids and solutions are high. All spontaneous processes (molecular scattering) have their analogies in stimulated processes i.e. they are really ASER amplifier or generators. Macroscopically, $\varepsilon$ undergo big change and dispersions are negligible regarding nonlinear contribution. The relations between $\varepsilon, \rho \mathrm{i} \rho \mathrm{d} \varepsilon / \mathrm{d} \rho$, have a role in holography, dynamical, selfdifraction, dynamical gratings, 4-photon mixing. Anomalous effects are not rare. The highest changes of $n$ considering values of $R_{\text {is }}$ and $R_{\text {aniz }}$ for quinoline, $C_{6}, H_{6}$, toluene and phytol have expressive anisotropy fluctuations and by $\mathrm{CCl}_{4}$ overcome isotropic ones.

\section{Acknowledgements}

The financial support of this research work was provided by the ministry of Education and Science of the Republic of Serbia through the project III-45005.

\section{REFERENCES}

[1] R.M. Wood,Laser Damage in Optical Materials, Adam Hilger ,Bristol,1986.

[2] N. Ambrozić, J.Radonjić, Optimization methods for detection of antibiotics in meat industry wastewater. Zbornik radova fak.tehn. nauka, 2013, pp.14621465, Novi Sad.

[3] M.Srećković, N.Ivanović, O. Žižić, S.Bojanić, (2003) J. Elec. Mat., Vol.32, iss.4, pp.208-214,
[4] O.L., Anderson, R.C.,Liebermann Vesiac State of the Art Report 7885-4-X,1966.

[5] M. Srećković (1981) Application of the laser light scattering method to the measurement of the sound velocity of organic solvents and the material structure, J. of Eng. Phys., XXIII, pp.19-32.

[6] M. Srećković, (1982), The structure of liquids and sound velocity, J.Eng. Phys.,XXIVpp.63- 80.

[7] M. Srećković (1980) La diffusion de la lumière du laser et les compressibilites isothermes de quelques solvent organiques, Journ of Eng. Phys., XX, pp.3952

[8] Z. Fidanovski, M.Srećković (1996) Hertzian Spectroscopy of phytol and its solutions, Interpretation of dynamic and constant of the system, J.Serb.Chem Soc.,61(9), pp.777-783

[9] M. Srećković,S .Blanchard, A.M.Tistchenko, J.P. Leicknam (1986) Rapports de Rayleigh, constantes de Rayleigh isotropes and anysotropes, facteurs de diffusion moleculaire anisotropes $\left(F_{\text {an }}\right)$ et anisotropies optiques mole-culaire du phytol et de quelque solvantes organique mesurees a $632.8 \mathrm{~m}$, avec un laser He-Ne, Port.Phys.,17 pp.181-202

[10]Z. Fidanovski, M. Srećković, S. Ostojić, J. Ilić , M. Mercle (2012) The interpretation of the intensity of components of laser scattering by interaction with matter, Phys. scr. T149, no.014016.

[11] M. Srećković, S. Ostojić, et al. (2010.) Scattering, reflection,transmission in theory and practice ,the estimation of nonlinear and ultrafast phenomena, Atti fond. Ronchi, LXV(13) pp.543-555

[12] S.A. Ahmanov, B.I.Koroteev, Metodi nelinejnoj optiki v spektroskopii, Nauka, Moskva, 1981.

[13] M. Srećković, B.Kaluđerović,et al. Optical Material Performances, Measurement by Laser implementation and Interpetations, Inženjerstvo, ekologija i materijali u procesnoj industriji, pp.23-30,Jahor., 2013

[14] M. Upadhyay and B.S. Sharma (2011) Analysis of sound velocities and elastic moduli of some minerals, Ind. J .of Pure and Applied Physics, 49, pp. 3034.

[15] Miceloobrazovanie, solubilizacija i microemulzii, Ed. K.L. Mittal, Mir, Moskow ,1980

[16] M. Srećković, Merenja rasejanja HeNe lasera (integralnog tipa) na talasnoj dužini $632.8 \mathrm{~nm}$ na smešama fitol-cikloheksan i molarna refrakcija“, X jugoslovenski simpozijum o merenjima i mernoj opremi, JUKEM 82, pp 277-287, Budva, 1982.

[17] M. Kerker, Scattering of Light and Other Electromagnetic Radiations,Academic Press, New York, 1969.

\section{IZVOD}

\section{NEKA RAZMATRANJA ODNOSA KVANTNE ELEKTRONIKE, AKUSTIKE I NAUKE O MATERIJALU BAZIRANE NA EKSPERIMENTU I TEORIJI}

Sprezanje nekih fundamentalnih nauka i mogući izlazi koji proističu se razmatraju u ovom radu. Savremeni problemi nauke o materijalima su vezani za transportne i optičke karakteristike. Neka merenja i njihove interpretacije za izabrane materijale kondenzovanog stanja su razmotreni. Razni procesi, koji uključuju direktne optičke $i$ akustične procese su mereni za materijale čvrstog i tečnog stanja. Prema osnovnim rezultatima merenja, razmotreno je dalje sprezanje. Glavne veze uključuju dielektrične, otporne, optičke $i$ akustične osobine. Nelinearni optički doprinosi, koji dovode do optičkog-laserskog proboja, može se oceniti iz linearnih podataka. Rasejanje laserskih snopova na micelama pokriva i prelazne procese i jedna je od aktuelnih oblasti u mnogim naukama (uključujući biologiju i ekologiju).

Ključne riječi: rasejanje, laser, micele, brzina zvuka, ekologija, transportne osobine, difuzija.

Pregledni rad

Rad primljen 20. 02. 2015.

Rad prihvace: 22. 04. 2015. 